\title{
The potential effects of Ankaferd blood stopper and fibrin sealent on sleeve gastrectomy staple-line healing: An experimental study
}

\author{
ALKAN SAKAR $^{1}$, TUNA BILECIK ${ }^{2}$, BURHAN MAYIR $^{3}$ and TAHIR ORUÇ ${ }^{3}$ \\ ${ }^{1}$ Department of General Surgery, Kepez State Hospital, Antalya 17110; ${ }^{2}$ Department of General Surgery, \\ School of Medicine, VM Mersin Medical Park Hospital, Istinye University, Mersin 33200; \\ ${ }^{3}$ Department of General Surgery, Antalya Training and Research Hospital, Antalya 07010, Turkey
}

Received September 24, 2018; Accepted April 26, 2019

DOI: $10.3892 /$ etm.2019.7842

\begin{abstract}
Staple-line bleeding and leakage is a life-threatening complication in obese patients following laparoscopic sleeve gastrectomy. The aim of this study was to examine the potential effects of Ankaferd blood stopper (ABS) and Fibrin Sealant (FS; Tissee ${ }^{\circledR}$ ) on sleeve gastrectomy staple-line healing in an experimental animal model. A total of 30 Wistar albino female rats were divided into three groups and were subjected to sleeve gastrectomy with linear stapling. Group A (control group) had nothing administered, Group B was administered FS on the staple-line, and Group $\mathrm{C}$ was administered ABS on the staple-line following sleeve gastrectomy. After sacrifice on postoperative day 5, anastomotic burst pressure, tissue hydroxyproline levels and histopathological parameters were measured. The results revealed that group $\mathrm{C}$ had the highest mean bursting pressure level. However, the values of this parameter were not found to differ significantly between the groups $(\mathrm{P}>0.05)$. Group $\mathrm{B}$ and $\mathrm{C}$ had a similar hydroxyproline levels but increased compared with group A $(\mathrm{P}<0.001)$. Histopathological parameters were similar between the groups, except macrophage scores in group $\mathrm{C}$. In the present experimental study, ABS was demonstrated to improve gastric-sleeved staple-line healing compared with FS. ABS may be used as a novel reinforcement agent in bariatric surgery.
\end{abstract}

\section{Introduction}

Laparoscopic sleeve gastrectomy (LSG) is a popular bariatric procedure in obese patients for weight loss and improves obesity-related comorbidities such as arterial hypertension, diabetes mellitus, obstructive sleep apnea and

Correspondence to: Dr Tuna Bilecik, Department of General Surgery, School of Medicine, VM Mersin Medical Park Hospital, Istinye University, 5 GMK Bulvarı, Mezitli/Mersin 33200, Turkey

E-mail: tunabilecik@gmail.com

Key words: obesity, laparoscopic sleeve gastrectomy, Ankaferd blood stopper, fibrin sealent dyslipidemia $(1,2)$. The major complications of LSG are leak and staple-line bleeding despite technical developments and surgical improvements in bariatric surgery $(3,4)$. The incidence of leak after LSG and staple-line hemorrhage has been reported to be $0-8$ and $0-8.7 \%$ respectively $(5,6)$. In order to prevent these major complications, several synthetic or biological reinforcement materials, such as fibrin sealant and/ or gelatin matrix agents, Seamguard, clips and sutures has been used following LSG $(4,7,8)$. However, there are controversial studies regarding the best method for staple-line reinforcement or its necessity in the current literature $(4,8,9)$.

Fibrin sealant (FS; Tisseel) is an agent that provides hemostasis, sealing and adhesion and it has a wide area of use in various surgical procedures $(10,11)$. In their study, Coşkun $\mathrm{H}$ and Yardimcı (4) suggested that FS is a reliable and useful agent to reinforce the staple-line and may prevent twists in the sleeved stomach.

Ankaferd blood stopper ${ }^{\circledR}$ (ABS) is a previously developed topical hemostatic agent containing a standardized mixture of the plants Thymus vulgaris, Glycyrrhiza glabra, Vitis vinifera, Alpinia officinarum and Urtica dioica (12). Through its effects on the endothelium, blood cells, angiogenesis, cellular proliferation, vascular dynamics and cell mediators; ABS is shown to have hemostatic and regenerative proliferation effects in in vivo and in vitro studies $(13,14)$. The topical use of $\mathrm{ABS}$ has been approved by the Turkish Ministry of Health for the management of postsurgical bleeding (12).

In this experimental study, the aim was to compare the effects of ABS and FS in terms of bursting pressure measurement, hydroxyproline and histological examination in resected sleeve gastrectomy specimens of rats. To the best of our knowledge, this is the first study investigating the potential effects of ABS as well as FS on staple line healing in an experimental study.

\section{Materials and methods}

This animal study was performed after the approval of Akdeniz University Experimental Animal Studies Local Ethical Committee (Ethical committee no: B.30.2.AKD.0.05.07.00/120). A total of 30 adult female Wistar Albino rats weighing between 200 and $250 \mathrm{~g}$ were obtained from the Akdeniz University Department 
of Experimental Animals Care and Production Unit (Konyaalt1/Antalya, Turkey). The rats were kept in standard colony cages $(15 \times 25 \times 40 \mathrm{~cm})$ under controlled conditions including temperature $\left(18^{\circ} \mathrm{C}\right)$, light (12-h light-dark cycle) and humidity (50-55\%). The rats were fed with the standard rat chow and tap water ad libitum during the experimental procedure except $12 \mathrm{~h}$ fasting period before the surgery.

After a 12-h fast, subjects were anesthetized using an intraperitoneal injection of $10 \mathrm{mg} / \mathrm{kg}$ xylazine (Bayer AG, Leverkusen, Germany) and $50 \mathrm{mg} / \mathrm{kg}$ of ketamine hydrochloride (Eczacibasi Holding A.S., Istanbul, Turkey). All surgeries were performed by a single surgeon blind to the subjects' grouping. After cleaning the skin with $10 \%$ povidone iodine (Central Laboratory, Istanbul, Turkey), a $3.5-4 \mathrm{~cm}$ midline laparotomy was made to access the abdominal cavity. The stomach was identified and the gastrosplenic ligament was ligated with $6 / 0$ polyglycolic sutures and divided. The great omentum was ligated with $6 / 0$ polyglycolic sutures and divided down to the level of pylorus. A part of the pylorus was left intact by starting the excision of the stomach 3-5 mm above the level of the pylorus, in order to maintain the free passage of the food to the duodenum. Stitches were placed defining the incision line, which contained the gastric fundus. The stapler (two rows, $3.5 \mathrm{~mm}$ height $-1.5 \mathrm{~mm}$ when closed; Echelon Flex powered vasculer stapler; Ethicon, Endo-Surgery, Inc., Cincinnati, OH, USA) was positioned on that line and the great curvature along with the gastric fundus was removed, leading to a drastic reduction of the gastric volume of $70-80 \%$ (Sleeve gastrectomy model; Fig. 1). An orogastric tube was not used during the excision of the stomach.

There were 3 experimental groups studied: Group A (control group)-only sleeve gastrectomy was performed $(\mathrm{n}=10)$; Group B-was administered a $4 \mathrm{ml}$ box FS on staple-line after sleeve gastrectomy by spray method $(n=10)$; and Group C-was administered 0.2 cc of ABS topically using an insulin injector on staple-line after sleeve gastrectomy $(\mathrm{n}=10)$. The abdominal wall was closed with running $3 / 0$ polyglycolic suture and the skin was sewed with a $4 / 0$ running intracutaneus suture.

Measurement of staple-line bursting pressure. On postoperative day 5 , the abdomen was reopened and the sleeved stomach was located. Thereafter, total gastrectomy was made in all subjects. A 8-French catheter was fixed with 2/0 silk suture through in pylorus which was connected to a metilen perfusion pump (Samtronic ST670 infusion pump; Samtronic, São Paolo, Brazil). An intracet was also fixed with $2 / 0$ silk suture through the esophagus that is connected to a monitor (Datex-Ohmeda, Compact Anesthesia Monitor; GE Healthcare, Chicago, IL, USA) by a pressure transducer (Transpac IV; Abbbott Laboratories, IL, USA). In order to measure bursting pressure, $6 \mathrm{ml} / \mathrm{min}$ of methylene blue was infused into the gastric lumen through the catheter, which is inserted into the pylorus using the perfusion pump and was monitored. The pressure level at the time of fluid leakage or a sudden pressure drop occurred was recorded. After the bursting pressure had been measured, the staple line segment was resected and divided into two equal parts passing through the anastomosis. One part was put in $10 \%$

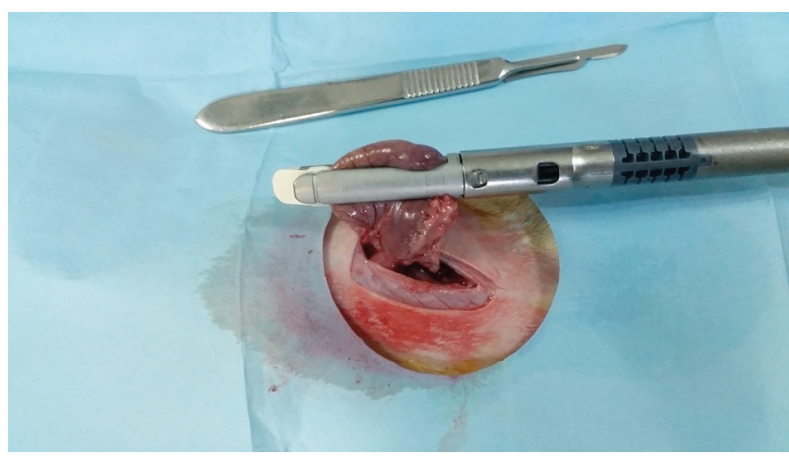

Figure 1. Sleeve gastrectomy model.

formaldehyde solution for $12 \mathrm{~h}$ and maintained at $4^{\circ} \mathrm{C}$ for histopathological examination and the other was frozen at $-80^{\circ} \mathrm{C}$ for measurement of hydroxyproline levels.

Hydroxyproline analysis. Tissue samples were weighed, cut into small pieces and homogenized in a PBS ( $\mathrm{pH} 7.4)$ with a sonicator for $10 \mathrm{~min}$ at $20^{\circ} \mathrm{C}$ and $35 \mathrm{kHz}$ (Bandelin Electronic, GmbH \& Co. KG., Berlin, Germany) for hydroxyproline levels determination. The homogenates were immediately centrifuged at $1,008 \mathrm{xg}$ for $20 \mathrm{~min}$, at $4^{\circ} \mathrm{C}$ and supernatants were collected. The supernatants were kept on ice. Supernatants were used for the measurement of hydroxyproline levels on the same day. Hydroxyproline levels were measured spectrophotometrically (Multiscan Spectrum; Thermo Labsystems, Santa Rosa, CA, USA) using a SunRed Rat Hydroxyproline ELISA kit (Shanghai SunRed Biological Technology Co., Ltd., Shanghai, China; cat. no. 201-11-0512). The hydroxyproline values were expressed as microgram per gram of tissue $(\mu \mathrm{g} / \mathrm{g})$.

Histopathological examination. Formalin-fixed tissue samples were embedded in paraffin and $4.5 \mu \mathrm{m}$ sections were cut. Replicate sections were either stained with hematoxylin and eosin for the evaluation of morphological features under a light microscope (BX51; Olympus Corporation, Tokyo, Japan) by a single pathologist blind to the sections' grouping. Tissues taken from the perianastomotic section were histopathologically examined for scoring of mucosal ischemia, anastomotic wound healing, granulation tissue formation and histological changes in local inflammatory response according to the criteria described by Biert et al (15) and modified by Verhofstad et al (16).

Statistical analysis. Descriptive statistics (mean \pm standard deviation) were determined and the results were used to produce charts in which the $95 \%$ confidence interval error bars indicate the means. The results of the analysis of the bursting pressure and the tissue hydroxyproline level were analyzed using the Shapiro-Wilks. Nonparametric measurements and comparisons of the three groups in terms of pathology were performed using the Kruskal-Wallis test. Comparisons of the two groups in terms of tissue hydroxyproline levels, bursting pressure and pathology were made using the Mann-Whitney U test with Bonferroni correction. IBM SPSS Statistics ver. 22.0 PASW 22 (IBM Corp., Chicago, IL, USA), was used to 
determine the statistical significance of the results. $\mathrm{P}<0.05$ was considered to indicate a statistically significant difference.

\section{Results}

There was no mortality because of anesthesia and surgical operations in any group during the study period. Bursts had occurred from staple-line anastomosis in all subjects. The fluid leakage site was the gastric fundus in all rats. Although the mean bursting pressure value was increased in group $\mathrm{C}$ compared with in groups A and B, no statistically significant differences was found among the group values $(\mathrm{P}=0.754$ Table I). Additionally there was no significant statistically difference of binary comparison of groups (Table II).

The results of the hydroxyproline levels among all groups are summarized in Tables III and IV. Analysis of the mean tissue hydroxyproline levels revealed statistically significant differences between groups $\mathrm{A}$ and $\mathrm{B}$ and between groups $\mathrm{A}$ and $\mathrm{C}(\mathrm{P}<0.001$ and $\mathrm{P}<0.001$, respectively). Group $\mathrm{C}$ had the highest mean level however there was no statistically significant differences between group $\mathrm{B}$ and $\mathrm{C}(\mathrm{P}>0.05)$. Based on these data, it was concluded that administration of ABS and FS has significant effect on the sleeved stapled-line in terms of tissue hydroxyproline levels.

The results of histopathological examination scores of the groups are given in Table V. Analysis of the groups in terms of necrosis, polymorphonuclear leukocyte, lymphocyte intensity, edema, mucosal epithelial damage and submucosal-mucosal bridging scores revealed the absence of any statistically significant differences among the groups. Group A had the highest macrophage score among all groups and there was statistically significant differences between groups $(\mathrm{P}=0.002)$. In the binary comparison of the macrophage score between groups, there was statistically significant differences between group $\mathrm{A}$ and $\mathrm{C}(\mathrm{P}=0.002$; Table VI).

\section{Discussion}

In this experimental study, the effects of FS and ABS on staple-line bursting pressure measurement, hydroxyproline level and histopathological examination in a sleeve gastrectomy model have been evaluated. It has been demonstrated that ABS and FS had better results on bursting pressure levels and tissue hydroxyproline levels in sleeved staple-line of rats. However, both ABS and FS had no effect at histopathological examinations of all groups. To the best of our knowledge, there is no study investigating the effects of FS and ABS in an experimental model of sleeve gastrectomy.

Staple-line leak and bleeding are the most common complications of LSG associated with significant morbidity and mortality (17). The hematoma formation and/or postoperative bleeding at the sleeved staple-line of the stomach can interfere with wound healing and could lead to a leak (18). In order to reduce these major complications of LSG, different surgical techniques and stapler line reinforcement materials have been defined and used. Although a number of studies have been carried on this topic, there is no enough evidence to support the necessity of reinforcement and/or hemostatic agents in $\operatorname{LSG}(9,19)$.
Table I. Staple-line bursting pressure measurements.

\begin{tabular}{lcc}
\hline Group & Mean \pm SD $(\mathrm{mmHg})$ & P-value $^{\mathrm{a}}$ \\
\hline Group A (Control) & $7 \pm 5.98$ & 0.754 \\
Group B (FS) & $10 \pm 13.35$ & \\
Group C (ABS) & $23.9 \pm 33.32$ & \\
\hline
\end{tabular}

Data were calculated using a Kruskal Wallis test. ${ }^{\text {aP-value between }}$ the three groups. FS, fibrin sealent; ABS, Ankaferd blood stopper; $\mathrm{SD}$, standard deviation.

Table II. Binary comparison of Staple-line bursting pressure levels among all groups.

\begin{tabular}{lccc}
\hline Measurements & $\mathrm{P}^{\mathrm{a}}$ & $\mathrm{P}^{\mathrm{b}}$ & $\mathrm{P}^{\mathrm{c}}$ \\
\hline Tissue bursting pressure (mmHg) & 0.909 & 0.061 & 0.074
\end{tabular}

Data were calculated using a Mann Whitney U test. ${ }^{\text {aP}} \mathrm{P}-\mathrm{value}$, group A vs. group $\mathrm{B}$; ${ }^{\mathrm{b}} \mathrm{P}-\mathrm{value}$ between groups $\mathrm{A}$ vs. $\mathrm{C}$; ${ }^{\mathrm{C}} \mathrm{P}$-value, group $\mathrm{B}$ vs. group C. Group A, control group; group B, fibrin sealent group; group $\mathrm{C}$, Ankaferd blood stopper group.

Table III. Tissue hydroxyproline levels ( $\mu \mathrm{g} / \mathrm{g}$ wet tissue).

\begin{tabular}{lcc}
\hline Group & Mean \pm SD & P-value $^{\mathrm{a}}$ \\
\hline Group A (Control) & $1.919 \pm 0.366$ & $\mathrm{P}<0.001$ \\
Group B (FS) & $5.639 \pm 1.031$ & \\
Group C (ABS) & $5.89 \pm 0.87$ & \\
\hline
\end{tabular}

Data were calculated using a Kruskal Wallis test. ${ }^{\mathrm{a} P}$-value between the three groups. FS, fibrin sealent; ABS, Ankaferd blood stopper; SD, standard deviation.

Table IV. Binary comparison of the tissue hydroxyproline levels among the study groups.

\begin{tabular}{lccc}
\hline Measurements & $\mathrm{P}^{\mathrm{a}}$ & $\mathrm{P}^{\mathrm{b}}$ & $\mathrm{P}^{\mathrm{c}}$ \\
\hline $\begin{array}{l}\text { Hydroxyproline/wet } \\
\text { tissue weight }(\mu \mathrm{g} / \mathrm{g})\end{array}$ & $<0.001$ & $<0.001$ & $>0.05$ \\
\hline
\end{tabular}

Data were calculated using a Mann Whitney U test. ${ }^{\mathrm{a}} \mathrm{P}$-value, group A vs. group B; ${ }^{\mathrm{P}}$-value between groups A vs. $\mathrm{C}$; ${ }^{\mathrm{C}} \mathrm{P}$-value, group $\mathrm{B}$ vs. group $\mathrm{C}$. Group $\mathrm{A}$, control group; group $\mathrm{B}$, fibrin sealent group; group C, Ankaferd blood stopper group.

ABS has been shown to have hemostatic and regenerative proliferation effects in in vivo and in vitro studies $(13,14)$. In addition, ABS has also been reported to have antimicrobial, antifungal, wound healing-enhancing effects and antiseptic properties in a small number of animal studies and case reports $(13,14)$. It has been known that collagen 
Table V. Results of histopathologic examination scores.

\begin{tabular}{lcccc}
\hline Variable & Group A (mean \pm SD) & Group B (mean \pm SD) & Group C (mean \pm SD) & $P^{a^{a}}$ \\
\hline Necrosis & $1.1 \pm 0.88$ & $0.5 \pm 0.53$ & $0.4 \pm 0.52$ & 0.109 \\
PMNL & $1.6 \pm 0.7$ & $1.3 \pm 0.48$ & $1.6 \pm 0.84$ & 0.350 \\
Lymphocyte & $1.6 \pm 0.70$ & $1.9 \pm 0.57$ & $1.6 \pm 0.84$ & 0.413 \\
Macrophage & $1.5 \pm 0.71$ & $1.1 \pm 0.57$ & $0.3 \pm 0.48$ & 0.002 \\
Edema & $1.2 \pm 0.63$ & $0.9 \pm 0.57$ & $0.8 \pm 0.42$ & 0.254 \\
Mucosal epithelium & $1.3 \pm 0.95$ & $1.2 \pm 0.79$ & $1.2 \pm 0.79$ & 0.894 \\
Submucosal-mucosal & $1.3 \pm 0.82$ & $1.0 \pm 0.67$ & $1.1 \pm 0.74$ & 0.602
\end{tabular}

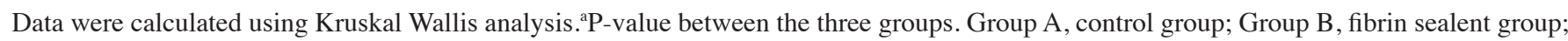
Group C, Ankaferd blood stopper group; SD, standard deviation.

Table VI. Binary comparison of the histopathologic examination scores of the groups.

\begin{tabular}{lccc}
\hline Variable & $\mathrm{P}^{\mathrm{a}}$ & $\mathrm{P}^{\mathrm{b}}$ & $\mathrm{P}^{\mathrm{c}}$ \\
\hline Necrosis & 0.104 & 0.061 & 0.661 \\
PMNL & 0.159 & 0.531 & 0.276 \\
Lymphocyte & 0.251 & 0.866 & 0.249 \\
Macrophage & 0.131 & 0.002 & 0.006 \\
Edema & 0.264 & 0.111 & 0.689 \\
Mucosal epitelium & 0.681 & 0.681 & 0.999 \\
Submucosal-mucosal & 0.328 & 0.516 & 0.737 \\
\hline
\end{tabular}

Data were calculated using a Mann Whitney U test. 'P-value, group A vs. group B; ${ }^{\mathrm{b}} \mathrm{P}$-value between groups $\mathrm{A}$ vs. $\mathrm{C}$; ${ }^{\mathrm{C}} \mathrm{P}$-value, group $\mathrm{B}$ vs. group $\mathrm{C}$. Group $\mathrm{A}$, control group; group $\mathrm{B}$, fibrin sealent group; group C, Ankaferd blood stopper group; PMNL, polymorphonuclear lymphocytes.

production is the main indicator of the healing process. Hydroxyproline is a measure of collagen content that has a positive correlation with the anastomose strength (20). In their study, Gulden et al (20) investigated the effects of ABS on colon anastomosis in an experimental study. The authors found that the levels of tissue hydroxyproline, an important indicator of anastomosis healing, were statistically significantly higher in ABS administered group (20). In the present study it was seen that ABS increased the bursting pressure on the stapler-line. Similar to Gulden et al study, it was demonstrated that topical use of ABS had improved tissue hydroxyproline levels on sleeved staple-line. In contrast to the Gulden et al study, although higher bursting pressure levels were observed in ABS administered group, there was no significant difference between the groups. The present study found that histopathological parameters were similar between the groups, except macrophage scores. The lowest macrophage score was found in group C. Previous studies reported that the higher macrophage score is correlated with poor wound healing $(15,16)$. As a result of this the present study concluded that ABS may improve wound healing. Since the rats were scarified on postoperative day 5 , further analysis with other markers of histopathological examination could provide different results in the same setting.

In the present study, apart from ABS and the control group, the FS group was formed as a third group. FS is one of the most commonly used reinforcement agent for the staple line reinforcement in bariatric surgery, although it is efficacy is under debate in studies $(4,9)$. For this reason, the present experimental study was designed to investigate the compatible efficiencies of ABS and FS. It was demonstrated that staple-line burst pressure and tissue hydroxyproline levels were increased in the ABS group compared with the FS group. The histopatological scores were similar also in the FS group compared with other groups. Based on these data, it was concluded that ABS may be an alternative to FS as a reinforcement agent in bariatric surgery.

The present study has several limitations. First of all, the present study was an animal study carrying all bias associated with the differences in animal and human metabolisms. Secondly, in this experimental study, a formal sleeve gastrectomy was not performed in rats as in humans. Third, only hydroxyproline levels were evaluated as a separate biochemical parameter and no immuno-histochemical study was conducted. In addition a light microscope was used for the evaluation of histopathological features. Further histopathological analyses under electron microscopy could give different results. As a result of these limitations, results similar to the present study may not be obtained in humans.

In conclusion, it was first demonstrated that ABS as well as FS improved staple line healing in terms of burst pressure and at tissue hydroxyproline level in an experimental study. Although there was no statistically significant difference between effects of ABS and FS on staple-line healing, it was suggested that ABS can be used with similar efficacy instead of FS as a novel reinforcement agent in bariatric surgery. The results of the present study should be supported by further experimental and clinical studies.

\section{Acknowledgements}

Not applicable.

\section{Funding}

No funding was received. 


\section{Availability of data and materials}

The datasets used and/or analyzed during the present study are available from the corresponding author on reasonable request.

\section{Authors' contributions}

AS conceived and designed the present study; TB conceived/designed the current study, collected data and wrote the article. BM acquired, analyzed and interpreted the data. TO made critical revisions to the manuscript and conceived/designed the current study. All authors read and approved the final version of the manuscript.

\section{Ethics approval and consent to participate}

The present animal study was performed after the approval of Akdeniz University Experimental Animal Studies Local Ethical Committee (Ethical committee no: B.30.2.AKD.0.05.07.00/120).

\section{Patient consent for publication}

Not applicable.

\section{Conflict of interest}

The authors declare that they have no competing interests.

\section{References}

1. Choi YY, Bae J, Hur KY, Choi D and Kim YJ: Reinforcing the staple line during laparoscopic sleeve gastrectomy: Does it have advantages? A Meta-analysis. Obes Surg 22: 1206-1213, 2012.

2. D'Hondt M, Vanneste S, Pottel H, Devriendt D, Van Rooy F and Vansteenkiste F: Laparoscopic sleeve gastrectomy as a single-stage procedure for the treatment of morbid obesity and the resulting quality of life, resolution of comorbidities, food tolerance, and 6-year weight loss. Surg Endosc 25: 2498-2504, 2011.

3. Aurora AR, Khaitan L and Saber AA: Sleeve gastrectomy and the risk of leak: A systematic analysis of 4888 patients. Surg Endosc 26: 1509-1515, 2012.

4. Coşkun $\mathrm{H}$ and Yardımcı E: Effects and results of fibrin sealant use in 1000 laparoscopic sleeve gastrectomy cases. Surg Endosc 31: 2174-2179, 2017.

5. Moon Han S, Kim WW and Oh JH: Results of laparoscopic sleeve gastrectomy (LSG) at 1 year in morbidly obese Korean patients. Obes Surg 15: 1469-1475, 2005.

6. Gagner M, Deitel M, Kalberer TL, Erickson AL and Crosby RD: The second international consensus summit for sleeve gastrectomy, March 19-21, 2009. Surg Obes. Relat Dis 5: 476-485, 2009.
7. Consten EC, Gagner M, Pomp A and Inabnet WB: Decreased bleeding after laparoscopic sleeve gastrectomy with or without duodenal switch for morbid obesity using a stapled buttresses absorbable polymer membrane. Obes Surg 14: 1360-1366, 2004.

8. Gentileschi P, Camperchioli I, D'Ugo S, Benavoli D and Gaspari AL: Staple-line reinforcement during laparoscopic sleeve gastrectomy using three different techniques: A randomized trial. Surg Endosc 26: 2623-2629, 2012.

9. Chen B, Kiriakopoulos A, Tsakayannis D, Wachtel MS, Linos D and Frezza EE: Reinforcement does not necessarily reduce the rate of staple line leaks after sleeve gastrectomy. A review of the literature and clinical experiences. Obes Surg 19: 166-172, 2009.

10. Spotnitz WD: Fibrin sealant: The only approved hemostat, sealant, and adhesive-a laboratory and clinical perspective. ISRN Surg 2014: 203943, 2014.

11. Silecchia G, Boru CE, Mouiel J, Rossi M, Anselmino M, Morino M, Toppino M, Gaspari A, Gentileschi P, Tacchino R and Basso N: The use of fibrin sealent to prevent major complications following laparoscopic gastric bypass: Results of a multicenter, randomized trial. Surg Endosc 22: 2492-2497, 2008.

12. Gungor G, Goktepe MH, Biyik M, Polat I, Tuna T, Ataseven H and Demir A: Efficacy of Ankaferd blood stopper application on non-variceal upper gastrointestinal bleeding. World J Gastrointest Endosc 4: 556-560, 2012.

13. Deveci A, Coban AY, Tanrıverdi Caycı Y, Acicbe O, Taşdelen Fışgın N, Akgüneş A, Ozatlı D, U̧zun M and Durupınar B: In Vitro Effect of AnkaferdBloodStopper a Plant Extract Against Mycobacterium tuberculosis Isolates Mikrobiyol Bul 47: 71-78, 2013.

14. Isler SC, Demircan S, Cakarer S, Cebi Z, Keskin C, Soluk M and Yüzbaşioğlu E: Effects of folk medicinalplant extract Ankaferd blood stopper on early bone healing. J Appl Oral Sci 18: 409-414, 2010.

15. Biert J, Seifert WF, Verhofstad AA, Wobbes T, de Man BM, Hoogenhout J and Hendriks T: A semiquantitative histological analysis of repair of anastomoses in the rat colon after combined preoperative irradiation and local hyperthermia. Radiat Res 149: 372-371, 998.

16. Verhofstad MH, Lange WP, van der Laak JA, Verhofstad AA and Hendriks T: Microscopic analysis of anastomotic healing in the intestine of normal and diabetic rats. Dis Colon Rectum 44: 423-431, 2001.

17. Buchwald H, Avidor Y, Braunwald E, Jensen MD, Pories W, Fahrbach K and Schoelles K: Bariatric surgery: A systematic review and meta-analysis. JAMA 292: 1724-1737, 2004.

18. De Angelis F, Abdelgawad M, Rizzello M, Mattia C and Silecchia G: Perioperative hemorrhagic complications after laparoscopic sleeve gastrectomy: Four-year experience of a bariatric center of excellence. Surg Endosc 31: 3547-3551, 2017.

19. Wang Z, Dai X, Xie H, Feng J Li Z and Lu Q: The efficacy of staple line reinforcement during laparoscopic sleeve gastrectomy: A meta-analysis of randomized controlled trials. Int J Surg 25: $145-152,2016$

20. Gulden C, Teksoz S, Aytac E, Arikan AE, Erman H, Uzun H, Ozden F, Aydin O and Ozcan M: Effects of Ankaferd on Anastomotic Healing of Colon. J Invest Surg 27: 1-6, 2014.

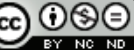

This work is licensed under a Creative Commons Attribution-NonCommercial-NoDerivatives 4.0 International (CC BY-NC-ND 4.0) License. 